\title{
Exclusion of the Left Atrial Appendage: A Safe, Reproducible and Effective Method
}

\author{
Abuin Gustavo ${ }^{1 *}$ and Desiderio Adrián ${ }^{2}$ \\ ${ }^{1}$ Director of the Heart laboratory at the ICAAP, University of Buenos Aires, Argentina \\ ${ }^{2}$ Director of the ICAAP, university of Buenos Aires (instituto de Ciencias anatómicas Aplicadas Florenzano), Argentina
}

Received: 些 June 27, 2018; Published: 跳 July 10, 2018

*Corresponding author: Gustavo Abuin Fray L Beltran, Director of the Heart laboratory at the ICAAP, University of Buenos Aires, School of Medicine, $207.2^{\circ}$ A. C.A.B.A-Argentina

\section{Abstract}

The exclusion of the left atrial appendage (LAA) in the setting of mitral valve surgery plays an important role in the prevention of strokes. We propose a method for the definitive closure of the LAA using an untreated autologous pericardial patch.

\section{Introduction}

The left atrial appendage (LAA) is a known source for thrombus formation specially in the setting of mitral valve disease [1]. Reversion to sinus rhythm after chronic atrial fibrillation is a cause for embolic events often resulting in major neurological impact2. Several methods for the closure of the LAA, both internal and external, have been proposed for stroke prevention. Pursestring closure of the LAA may not be appropriate in wide-based appendages due to the danger of disruption of the atrial wall. External closure, either by loops or stables, may cause injury to the circumflex artery or its branches. Excision of the LAA prolongs operating time, causes a deficiency of atrial natriuretic factor and may lead to life-threatening hemorrhage[1-3] (Figures 1 \& 2).

1: Circumflex artery

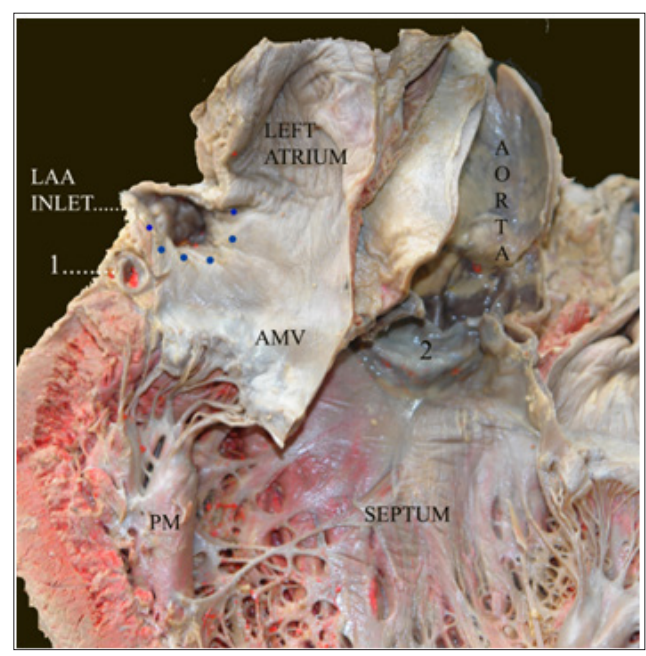

2: Aortic valve

AMV: anterior mitral valve

Dotted Lines: Suggested Line of Suture for Pericardial Patch

LAA INLET: Left Atrial Appendage Inlet

PM: Papillary Muscle

Figure 1. 


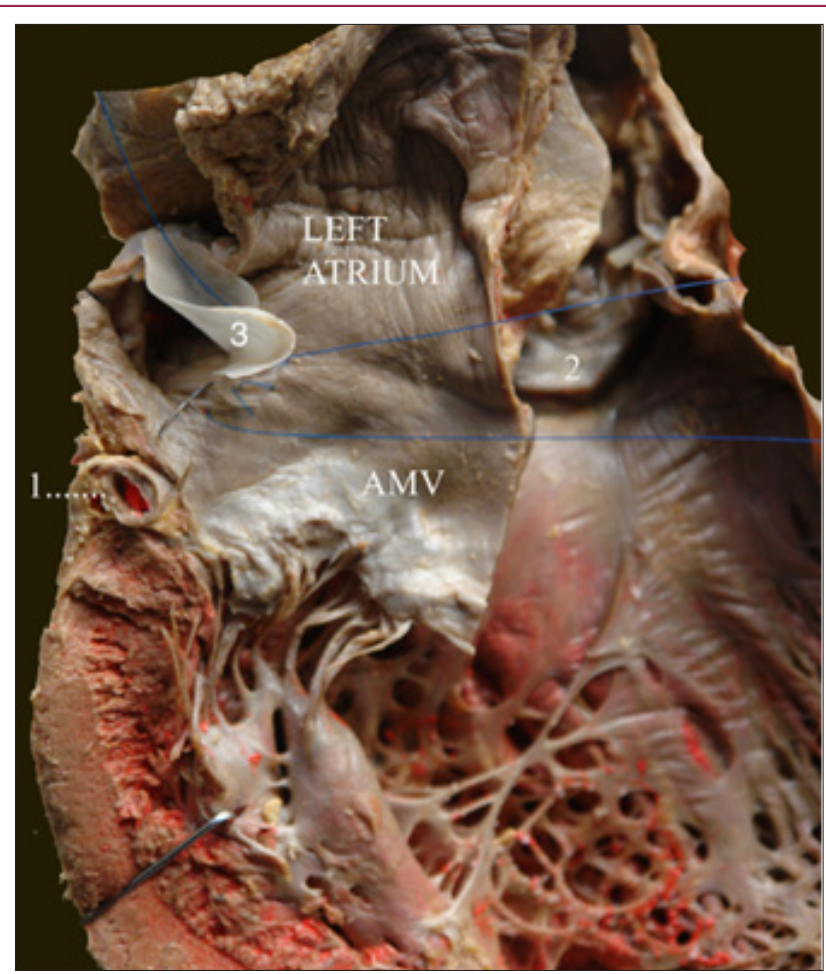

1: circumflex artery

2: aorta

3: pericardial patch

AMV: anterior mitral valve

Figure 2.

\section{Technique}

We propose here a safe method for intraoperative exclusion of the LAA when performing mitral valve procedures. On opening the left atrium the inlet of the LAA is inspected. The inlet is then closed off securely with a patch of fresh autologous pericardium by means of a running 4-0 prolene suture. This ensures a watertight closure with minimum tension, regardless of the diameter of the inlet, and takes very few minutes to perform. Attention can now be directed to the mitral valve. In the event of valve replacement we suggest performing the exclusion of the LAA first since the presence of prosthesis may encumber the procedure.

\section{Comment}

We believe that this method ought to prove superior to others, since it may be performed regardless of the inlet diameter, is less liable to cause lesion of the circumflex artery, does not risk a deficiency of the atrial natriuretic factor, it is not a cause of hemorrhage and does not increase pump time significantly. Most methods have a high index of recanalization3, excision of the LAA being the only exception to this complication. Our method of closure ensures successful exclusion without the need for excision.

\section{References}

1. Kamohara K, Fukamachi K, Ootaki Y, Masatoshi Akiyama, Faruk Cingoz, et al. (2006) Evaluation of a novel device for left atrial appendage exclusion: The second-generation atrial exclusion device. J Thorac Cardiovasc Surg 132(2): 340-346.

2. Blackshear JL, Odell JA (1996) Obliteration of the left atrial appendage to reduce stroke in cardiac surgical patients with atrial fibrillation. Ann Thorac Surg 61(2): 755-759.

3. Anne SKanderian, A MarcGillinov, Gosta B Pettersson, Eugene Blackstone, Allan LKlein (2008) Success of Surgical Left Atrial Appendage Closure: Assessment by Transesophageal Echocardiography Clinical Research Cardiac Surgery 52(11): 924-929. 
ISSN: 2574-1241

DOI: 10.26717/BJSTR.2018.06.001374

Abuin Gustavo. Biomed J Sci \& Tech Res

(C) This work is licensed under Creative

Submission Link: https://biomedres.us/submit-manuscript.php

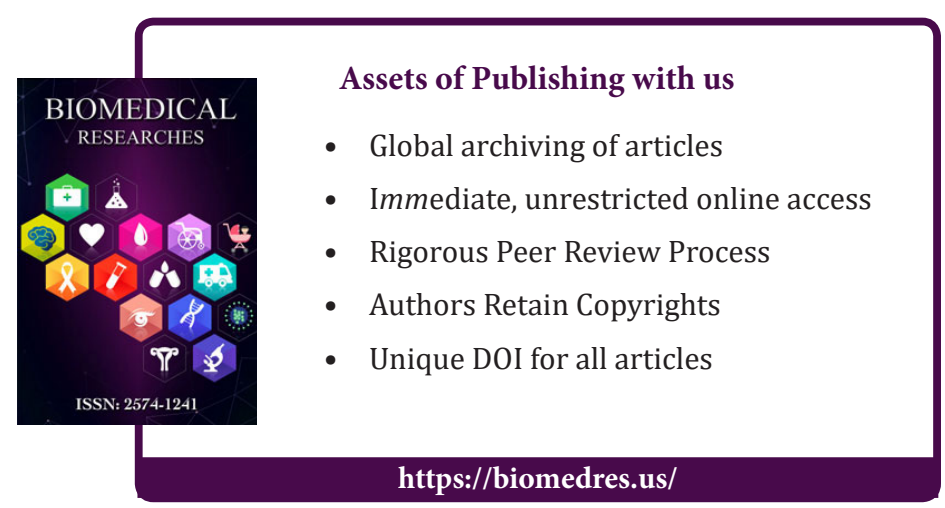

